\title{
Tweaking innate immunity: The promise of innate immunologicals as anti-infectives
}

\author{
Kenneth L Rosenthal PhD
}

KL Rosenthal. Tweaking innate immunity: The promise of innate immunologicals as anti-infectives. Can J Infect Dis Med Microbiol 2006;17(5):307-314.

New and exciting insights into the importance of the innate immune system are revolutionizing our understanding of immune defense against infections, pathogenesis, and the treatment and prevention of infectious diseases. The innate immune system uses multiple families of germline-encoded pattern recognition receptors (PRRs) to detect infection and trigger a variety of antimicrobial defense mechanisms. PRRs are evolutionarily highly conserved and serve to detect infection by recognizing pathogen-associated molecular patterns that are unique to microorganisms and essential for their survival. Toll-like receptors (TLRs) are transmembrane signalling receptors that activate gene expression programs that result in the production of proinflammatory cytokines and chemokines, type I interferons and antimicrobial factors. Furthermore, TLR activation facilitates and guides activation of adaptive immune responses through the activation of dendritic cells. TLRs are localized on the cell surface and in endosomal/lysosomal compartments, where they detect bacterial and viral infections. In contrast, nucleotide-binding oligomerization domain proteins and RNA helicases are located in the cell cytoplasm, where they serve as intracellular PRRs to detect cytoplasmic infections, particularly viruses. Due to their ability to enhance innate immune responses, novel strategies to use ligands, synthetic agonists or antagonists of PRRs (also known as 'innate immunologicals') can be used as stand-alone agents to provide immediate protection or treatment against bacterial, viral or parasitic infections. Furthermore, the newly appreciated importance of innate immunity in initiating and shaping adaptive immune responses is contributing to our understanding of vaccine adjuvants and promises to lead to improved nextgeneration vaccines.

Key Words: Anti-infectives; $\mathrm{CpG}$ DNA; Innate immunity; Microbicide; NOD1; NOD2; Pathogen-associated molecular patterns; Pattern recognition receptors; RNA helicases; Toll-like receptors; Vaccine adjuvant

\section{La modification de l'immunité innée : La promesse des adjuvants immunologiques comme anti-infectieux}

De nouveaux aperçus passionnants de l'importance du système immunitaire inné révolutionnent notre compréhension de la défense immunologique contre les infections, de la pathogenèse, du traitement et de la prévention des maladies infectieuses. Le système immunitaire inné fait appel à de multiples familles de récepteurs de reconnaissance des formes (RRF) codés dans les cellules germinales pour déceler l'infection et déclencher divers mécanismes de défense antimicrobienne. Les RRF sont hautement conservés pendant leur évolution, et ils permettent de déceler l'infection en reconnaissant les motifs moléculaires propres aux pathogènes uniques aux microorganismes et essentiels à leur survie. Les récepteurs Toll sont des récepteurs de signalisation transmembranaire qui activent les programmes d'expression génique, ce qui entraîne la production de cytokines et de chémokines pro-inflammatoires, d'interférons de type I et de facteurs antimicrobiens. De plus, l'activation des récepteurs Toll facilite et oriente l'activation des réponses immunitaires adaptatives par l'entremise de l'activation des cellules dendritiques. Les récepteurs Toll se trouvent à la surface des cellules et dans les compartiments endosomaux et lysosomaux, où ils détectent les infections bactériennes et virales. Par contre, les protéines du domaine de l'oligomérisation liant les nucléotides, de même que les hélicases de l'ARN, sont sises dans le cytoplasme des cellules, où elles servent de RRF intracellulaires pour dépister les infections cytoplasmiques, notamment les virus. Étant donné leur capacité de stimuler les réponses immunitaires innées, il est possible d'utiliser de nouvelles stratégies visant l'utilisation des ligands, des agonistes ou des antagonistes synthétiques des RRF (également désignés « adjuvants immunologiques innés ») à titre d'agents autonomes pour assurer une protection ou un traitement immédiat contre les infections bactériennes, virales ou parasitiques. De plus, la nouvelle appréhension de l'importance de l'immunité innée pour initier et modeler les réponses immunitaires adaptatives contribue à comprendre les adjuvants vaccinaux et promet de donner lieu à une prochaine génération de vaccins améliorés. 
$\mathrm{D}^{\mathrm{cos}}$ espite the fact that the development of antibiotics, vaccines and, more recently, antivirals has led to the view that infectious diseases might be easily controlled or even eradicated, infections remain a constant threat to the health of developing and developed nations. We are living in a time when the world is experiencing the worst pandemic in human history - the HIV pandemic. In 2003, severe acute respiratory syndrome quickly encircled the globe to infect 8400 people, with a rapidity dramatized by a 78-year-old woman carrying the infection from Hong Kong to Toronto and precipitating a chain reaction that caused 44 deaths in Canada. Twenty wellknown diseases, including tuberculosis (TB), malaria and cholera, have re-emerged or spread geographically, often in more virulent and drug-resistant forms. Collectively, HIV/AIDS, malaria and TB kill six million people per year. At least 30 previously unknown agents have been identified since 1973, including HIV, hepatitis C virus and Nipah virus, for which no cures are available. Importantly, recent concerns that the $\mathrm{H} 5 \mathrm{~N} 1$ avian influenza virus could rapidly cause anywhere between four and 150 million deaths in a short time are serving as a wake-up call that we, as a global society, must safeguard ourselves against an increasing number of infectious threats. New and exciting insights into activation and the importance of the innate immune system are revolutionizing our understanding of protection against infections and how vaccine adjuvants work. Based on this new understanding, it is increasingly being appreciated that enhancement or modulation of innate immunity through the use of 'innate immunologicals' holds great promise as an alternative strategy for the rapid control of infections and improved next-generation vaccines for longer-term control of specific infections.

\section{SENSING INFECTION: THE IMPORTANCE OF INNATE IMMUNITY}

The mammalian immune system has evolved multiple, layered and interactive defensive systems to protect against infections. These have been broadly divided into innate immunity and adaptive immunity. Innate immunity is the first line of defense against microbial pathogens and acts almost immediately to limit early proliferation and spread of infectious agents through the activation of phagocytic and antigen-presenting cells, such as dendritic cells (DCs) and macrophages, and the initiation of inflammatory responses through the release of a variety of cytokines, chemokines and antimicrobial factors, such as interferons (IFNs) and defensins. Innate immunity is evolutionarily ancient, and for many years its study was largely ignored by immunologists as relatively nonspecific. For the most part, though, we are protected against infection by our innate immune system. If infectious organisms penetrate these innate immune defenses, then our innate defenses facilitate and guide the generation of adaptive immune responses, which are directed against highly specific determinants that are uniquely expressed by the invading pathogen. These responses are dependent on the rearrangement of specific antigen-receptor genes in B cells and $\mathrm{T}$ cells and result in the production of high-affinity, antigenspecific antibodies (humoral immunity) and T cells (also known as cell-mediated immunity). In general, antibodies facilitate the removal, destruction or neutralization of extracellular pathogens and their toxins, whereas $\mathrm{T}$ cell-mediated immune responses help eliminate or control intracellular pathogens. In contrast with innate immune responses, adaptive immune responses have the hallmark of specific immune memory.
There are a number of key questions that have, until recently, been unanswered: how does the host innate immune system detect infection, and how does it discriminate between self and infectious nonself (pathogens)? The recent discovery and characterization of the toll-like receptor (TLR) family has provided great insight into innate immune recognition and established a key role of the innate immune system in host defense against infection (1-5). The innate immune system uses multiple families of germline-encoded pattern recognition receptors (PRRs) to detect infection and trigger a variety of antimicrobial defense mechanisms (6). These PRRs are evolutionarily highly conserved among species, ranging from plants and fruit flies to mammals. The strategy of innate immune recognition is based on the detection of highly conserved and essential structures present in many types of microorganisms and absent from host cells $(7,8)$. Because the targets of innate immune recognition are conserved molecular patterns, they are called pathogen-associated molecular patterns (PAMPs). PAMPs have three important features that make them ideal targets for innate immune sensing. First, PAMPs are produced only by microorganisms and not by host cells. This is the basis for the discrimination between self and infectious nonself. Second, PAMPs are conserved among microorganisms of a given class. This allows a limited number of PRRs to detect the presence of a large class of invading pathogens. For example, a pattern in lipopolysaccharide (LPS) allows a single PRR to detect the presence of any Gram-negative bacteria. Third, PAMPs are essential for microbial survival, and any mutation or loss of PAMPs are either lethal for the organism or greatly reduces their adaptive fitness. These new insights into innate immune recognition are revolutionizing our understanding of immune defense, pathogenesis, and the treatment and prevention of infectious diseases.

\section{WE STAND ON GUARD FOR THEE: TOLL-LIKE RECEPTORS}

TLRs represent one family of PRRs that are evolutionarily conserved transmembrane receptors that detect PAMPs and function as signalling receptors. TLRs were first discovered in Drosophila, where they play a role in the development of the ventral/dorsal orientation of fruit flies (9). When this gene was mutated, the flies that developed were found to be 'toll', which is German slang for 'crazy' or 'far out'. Furthermore, flies with mutation of Tolls were found to be highly susceptible to fungal infections (10). To date, 11 TLRs have been identified in mammals, each sensing a different set of microbial stimuli and activating distinct signalling pathways and transcription factors that drive specific responses against the pathogens (11). TLRs are type I integral membrane glycoproteins characterized by extracellular domains containing various numbers of leucine-rich repeat (LRR) motifs, a transmembrane domain and a cytoplasmic signalling domain homologous to that of the interleukin-1 receptor (IL-1R), which is termed the Toll/IL-1R homology (TIR) domain (12). The LRR domains are composed of 19 to 25 tandem LRR motifs, each of which is 24 to 29 amino acids in length.

TLR4, the first mammalian TLR discovered, proved to be the long sought-after receptor for Gram-negative bacterial LPS $(13,14)$. TLR2 recognizes peptidoglycan, in addition to the lipoproteins and lipopeptides of Gram-positive bacteria and mycoplasma $(15,16)$. TLR2 can form heterodimers with TLR1 or TLR6 to discriminate between diacyl and triacyl lipopeptides, 
respectively (15). Furthermore, TLR2, in collaboration with the non-TLR receptor dectin-1, mediates the response to zymosan, which is found in the yeast cell wall (17). TLR5 recognizes flagellin, a protein component of bacterial flagella (18). TLR11, a close relative of TLR5, was found to be abundantly expressed in the urogenital tract of mice and associated with protection against uropathogenic bacteria (19); it was also recently shown to recognize profilin-like protein from the protozoan parasite Toxoplasma gondii (20). TLR3, 7, 8 and 9 recognize nucleic acids and are not expressed on the cell surface, but are exclusively expressed in endosomal compartments $(21,22)$. TLR3 is involved in the recognition of double-stranded RNA (dsRNA) generated during viral infection (23), whereas the closely related TLR7 and TLR8 recognize viral singlestranded RNA rich in guanosine and uridine $(24,25)$ and synthetic imidazoquinoline-like molecules imiquimod (R-837) and resiquimod ( $\mathrm{R}-848)(26,27)$. TLR9 mediates the recognition of bacterial and viral unmethylated CpG DNA motifs (28) and was recently also shown to recognize non-DNA pathogenic components, such as hemozoin from malarial parasites (29).

TLRs can also be divided into six major subfamilies based on sequence similarity (30), each recognizing related PAMPS. The subfamily consisting of TLR1, TLR2 and TLR6 recognizes lipopeptides; TLR3 recognizes dsRNA; TLR4 recognizes LPS; TLR5 recognizes flagellin; the TLR9 subfamily, which includes highly related TLR7 and TLR8, recognizes nucleic acids; and the PAMP for the remaining family, TLR11, is unknown. Importantly, the subcellular localization of TLRs correlates with the nature of their ligands, rather than sequence similarity (2). TLR1, 2, 4, 5 and 6 are present on the surface plasma membrane, where they recognize bacterial and viral components, while antiviral TLRs, including TLR3, 7, 8 and 9, are expressed in intracellular endosomes. Because nucleic acids recognized by antiviral TLRs are also found in vertebrates, their location in endosomes limits their reactivity to self nucleic acids (31).

Signalling by TLRs is complex and has been reviewed elsewhere $(12,32)$. Briefly, all TLRs, with the exception of TLR3, signal through the adaptor molecule myeloid differentiation factor 88 , a cytoplasmic protein containing a TIR domain and a death domain. Ultimately, nuclear factor- $\mathrm{kB}$ and mitogenactivated protein kinases are activated downstream of tumour necrosis factor receptor-associated factor 6 , leading to the production of proinflammatory cytokines and chemokines, such as tumor necrosis factor-alpha, IL-6, IL-1 $\beta$ and IL-12. In addition to myeloid differentiation factor 88 , TLR3 and TLR4 signal through TRIF, another TIR-containing adaptor that is required for the production of type I interferons and type I interferon-dependent genes.

TLRs are expressed on a variety of immune and nonimmune cells. Murine macrophages express TLR1 through 9, reflecting their importance in the initiation of proinflammatory responses. Plasmacytoid DCs (pDCs) that produce large amounts of type I interferons during viral infections express TLR7 and 9. All conventional DCs in the mouse express TLR1, 2, 4, 6, 8 and 9, while TLR3 is confined to the CD8+ and CD4-CD8-DC subset (33). In humans, TLR9 expression is restricted to pDCs and B cells $(34,35)$. TLR3 is not expressed in pDCs of mice or humans. In addition to the focus of expression on immune cells, there is great interest in understanding the expression of TLRs on mucosal epithelial cells (ECs) that serve as the first line of defense against most infections. Studies by Xiao-Dan Yao and colleagues (36) have concentrated on understanding expression and regulation of TLRs on ECs in the genital tract of mice and humans. Most recently, they used laser capture microdissection to show that the estrous cycle in female mice profoundly influences expression of TLRs in the vaginal epithelium. Their findings showed that messenger RNA expression of essentially all TLRs, except TLR11, were significantly increased during diestrus and especially following treatment with the long-acting progestin Depo-Provera (Pfizer Inc, USA) (36). These findings should contribute to the understanding of innate immune defense against sexually transmitted infections (STIs) and enhance the quality of women's reproductive health.

TLRs induce a range of responses depending on the cell type in which they are activated $(33,37)$. For example, treatment of DCs with CpG DNA that acts through TLR9 activates the DCs to mature, including the upregulation of major histocompatibility complex class II and costimulatory molecules, the production of proinflammatory cytokines and chemokines, and the enhancement of antigen presentation. Similarly, treatment of B cells with $\mathrm{CpG}$ induces their activation and proliferation, the secretion of antibody, IL- 6 and IL-10, and the resistance of B cells to apoptosis. Activation of immune cells via CpG DNA induces a $\mathrm{T}$ helper (Th) type 1 -dominated response.

\section{CYTOPLASMIC PATHOGEN RECOGNITION RECEPTORS}

Although TLRs recognize PAMPs at the cell surface or in endosomal/lysosomal membranes, a number of pathogens invade the cytosol. These pathogens are detected by cytoplasmic PRRs. Recently, two families of these cytoplasmic receptors have been cloned, including the nucleotide-binding oligomerization domain (NOD)-LRR proteins $(38,39)$ and caspase-activation recruitment domain (CARD)-helicase proteins (40).

NOD-LRR proteins are implicated in innate immune recognition of specific motifs in bacterial peptidoglycan cell wall components. NOD1 and NOD2 are well studied members of this large family, which consists of over 20 proteins $(38,39)$. NOD1 and NOD2 proteins possess a C-terminal LRR domain that mediates ligand sensing, a centrally located NOD that mediates self-oligomerization, and an N-terminal CARD for transmitting signals. NOD1 detects gamma-D-glutamylmeso-diaminopimelic acid $(41,42)$ and NOD2 detects muramyl dipeptide $(43,44)$ found in bacterial peptidoglycan. Following ligand binding to NOD1 or NOD2, they oligomerize, which results in nuclear factor- $\mathrm{\kappa B}$ activation through the recruitment of the serine/threonine kinase RIP2/RICK via CARD:CARD interactions. NOD1 is expressed in most tissues, while NOD2 is limited to monocyte and granulocyte lineage and ECs (45-47). These NOD proteins synergize with each other and with TLRs in activating innate immune responses to invasive bacterial pathogens, especially inflammatory responses. A mutation in human NOD2 is correlated with susceptibility to Crohn's disease, an inflammatory bowel disease $(48,49)$. Thus, Crohn's disease may be the result of deficient innate immune defenses against bacterial infections in the gut. NOD1 participates in defense against Helicobacter pylori infection (50).

It has been increasingly recognized that there are TLRindependent mechanisms of sensing actively replicating viruses 
in the cytoplasm of infected cells through dsRNA. Indeed, most virus-infected cells secrete type I IFNs in a TLR3independent manner. CARD-helicase proteins were recently identified as detectors of cytoplasmic viral dsRNA (40). Retinoic acid-inducible protein-1 (RIG-1) and melanoma differentiation associated gene 5 (MDA-5) are intracellular RNA helicases that contain CARD domains and localize to the cytoplasm (3). These proteins are widely expressed and upregulated following positive feedback with type I IFNs (40). They recognize intracellular dsRNA and induce IFN- $\beta$

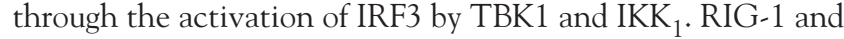
MDA-5 protect all cells once they have been infected with virus, while antiviral TLRs, including TLR7, 8 and 9 on specialized pDCs serve as sentinels of viral infection independent of viral tropism (51). Hepatitis $\mathrm{C}$ virus and paramyxoviruses produce proteins that interfere with activation of RIG-1 or MDA-5, respectively $(52,53)$. Thus, two innate antiviral pathways trigger type I IFNs in response to dsRNA. RNA viruses replicating in the cytoplasm are recognized by RIG-1, whereas TLR3 has been suggested to be responsible for recognizing dsRNA contained in apoptotic bodies of virus-infected cells taken up by DCs $(3,5)$. Overall, the various PRR families that have been recently identified serve to protect us by sensing infection at the cell surface, in endosomes/lysosomes inside of cells, and in the cytoplasm of host cells.

\section{INNATE IMMUNOLOGICALS AS ANTI-INFECTIVES}

The mechanisms by which PRRs mediate host defense against pathogens are the focus of intense research. Due to their ability to enhance innate immune responses, novel strategies to use ligands, synthetic agonists or antagonists of PRRs (also known as 'innate immunologicals') can be used as stand-alone agents to provide protection or treatment against infection with intracellular bacteria, parasites and viruses.

One of the earliest models tested examined whether $\mathrm{CpG}$ DNA, which acts through TLR9, could redirect a curative Th1 response in Balb/c mice infected with Leishmania major, a model for a lethal Th2-driven disease (54-56). Treatment of mice with $\mathrm{CpG}$-induced resistance that was associated with IL-12 and IFN- $\gamma$ production. Interestingly, CpG DNA cured mice when delivered as late as 20 days after lethal $L$ major infection, indicating that $\mathrm{CpG}$ can shift an established $\mathrm{Th} 2$ response to a protective Th1 response.

Similarly, mice treated with $\mathrm{CpG}$ DNA or synthetic CpG oligodeoxynucleotides (ODNs) were shown to resist infection from high doses of bacteria that cause anthrax, listeria (57), tularemia (58) and TB (59); from viruses such as herpes simplex virus (HSV) (60-62), cytomegalovirus and the biothreat agent Ebola virus (63); and from the parasites responsible for malaria and leishmaniasis.

Among infectious diseases, TB and malaria are among the leading causes of death worldwide. The problems associated with these infections have worsened due to the emergence of multidrug-resistant TB and the resistance of parasites to antimalarial drugs. Treatment of mice with $\mathrm{CpG}$ DNA one or two days before challenge with Plasmodium yoelii conferred sterile protection against infection (64). The protection was dependent on IL-12 and IFN- $\gamma$. Similarly, the treatment of mice with $\mathrm{CpG}$ at the time of, or two weeks after, intranasal infection with Mycobacterium tuberculosis enhanced survival and reduced mycobacterial outgrowth for up to five weeks in the lungs (59).
This was associated with a decrease in pulmonary inflammation and increased IFN- $\gamma$ and decreased IL- 4 in the lung.

The importance of augmentation of innate immunity by $\mathrm{CpG}$ was further demonstrated in a model of acute polymicrobial sepsis. Treatment of mice with CpG DNA six days before induction of acute polymicrobial peritonitis resulted in increased resistance to sepsis (65). This resistance was associated with augmented accumulation of neutrophils at the primary site of infection and enhanced antimicrobial activity of these cells. Thus, $\mathrm{CpG}$ may serve as a potent anti-infective for the treatment of sepsis. Alternatively, TLR2 or TLR4 antagonists may prove therapeutically useful in sepsis (66). A naturally occurring soluble form of TLR2 (sTLR2) has been identified from human blood monocytes (67). sTLR2 binds to soluble CD14 and limits tumour necrosis factor and IL-8 production in the presence of bacterial lipopeptides. Thus, sTLR2 may modify the endotoxin response. Similarly, a specific TLR4 antagonist, eritoran (E 5564), is now being studied in a doubleblind, placebo-controlled, human clinical trial to determine its ability to block the toxic effects of endotoxin in healthy volunteers $(68,69)$.

Although the natural ligands for TLR7 and TLR8 were recently identified as single-stranded RNA (25), small molecule agonists for TLR7 and 8 were already in use clinically against papillomavirus-induced genital warts. The imidazoquinolinelike molecules imiquimod and resiquimod are effective immunoadjuvants in eliminating genital warts (70). Now that the receptors for these synthetic compounds have been identified, it is possible that improved agonists will be developed.

Importantly, $\mathrm{CpG}$ ODNs have also been shown to improve the ability of immunosuppressed, pregnant and newborn animals to resist infection (71). For example, studies of pregnant mice show that $\mathrm{CpG}$ ODN treatment significantly increased resistance to infection by bacteria and reduced transplacental transmission of pathogen from mother to fetus (72).

\section{INNATE IMMUNOLOGICALS AS MUCOSAL MICROBICIDES}

Microbicides are topical compounds delivered to the vaginal and/or rectal mucosa that may prevent STIs (73). Indeed, they have been touted as a means of female-controlled HIV prevention for over a decade. However, the current strategies of microbicides in clinical trials are primarily based on substances that produce physical barriers or are based on the use of antiretroviral drugs incorporated into gels, creams or various delivery systems. These drug-based approaches are susceptible not only to the induction of local inflammation, but also to the same old problems encountered with the overuse of antibiotics.

More recent studies have demonstrated that a single dose of CpG ODN delivered transmucosally to the vaginal mucosa, in the absence of any viral antigen, protects against genital infection with lethal doses of HSV-2 (60). This protection was mediated by the innate immune system because it occurred in knockout mice lacking B cells and T cells. Local intravaginal (IVAG) delivery of $\mathrm{CpG}$ ODN resulted in rapid proliferation and thickening of the vaginal epithelium and induction of a TLR9-dependent antiviral state that did not block virus entry but inhibited viral replication in vaginal epithelial cells (60). More recently, it was determined that mucosal delivery of dsRNA, the ligand for TLR3, protected against genital HSV-2 infection without the local or systemic inflammation seen with CpG ODN (74). Therefore, local delivery of TLR3 ligand may 
be a safer means of protecting against genital viral infection. It is also highly likely that this innate immune-mediated antiviral state will protect against a variety of viral STIs, including HIV-1. Thus, topical application of these 'innate immunologicals' may rapidly activate our innate mucosal immune system and induce a local antiviral state, which protects mucosal surfaces against infection with sexually transmitted agents. Indeed, this approach may be safer and not susceptible to selection of resistant pathogens because it would use more 'natural microbicides', as well as evolutionarily ancient innate mucosal immune responses, for protection.

\section{TAKE THE TOLLWAY: INNATE IMMUNOLOGICALS AS VACCINE ADJUVANTS}

Most vaccines, with the exception of those made with replicating viruses, require an adjuvant to induce effective immune responses. Adjuvants, sometimes called 'the immunologist's dirty little secret', are defined as substances and formulations that increase immune responses to an antigen (75). They can also control the type of immune response elicited and, from a practical standpoint, can reduce the amount of antigen needed in a vaccine. Until recently, adjuvant research has been mostly empirical and lacking simplifying concepts of how these compounds work.

New insights into innate immunity have revolutionized our understanding of immune activation and the mechanisms underlying adjuvant activity. Activation of innate immunity through PRRs, such as the TLRs, induces a diverse array of antimicrobial molecules and effector cells, which attack microorganisms at multiple levels. Activation of innate immunity also leads to the release of cytokines and chemokines that recruit and activate many types of cells, including DCs and antigen-presenting cells, which are important for the transition from innate to adaptive responses. Thus, the activation of the innate immune system through PRRs using their respective ligands or agonists represents a strategy to enhance immune responses against pathogens, making PRRs excellent adjuvants.

In addition to enhancing innate immunity, TLR ligands and agonists have been well documented to enhance antigenspecific immune responses (76-82). For example, the ability of $\mathrm{CpG}$ to act as a potent adjuvant was confirmed in studies using model antigens, such as ovalbumin (79), and antigens from infectious agents, such as hepatitis B virus (77), influenza (83) and HSV (78). Furthermore, these studies showed that CpG serves as a potent adjuvant for both parenteral and mucosal vaccines (80). Although most of these studies made use of small animal models, $\mathrm{CpG}$ was also shown to markedly enhance the response of orangutans to hepatitis B immunization (84). Orangutans are normally hyporesponsive to current commercial hepatitis B vaccines. After two doses, however, $100 \%$ of animals immunized with vaccine plus CpG had protective levels of antibodies compared with only $8 \%$ of animals immunized with vaccine alone.

Similarly, in the first human trial of $\mathrm{CpG}$, two weeks after the first immunization of normal volunteers, $92 \%$ of the subjects receiving $\mathrm{CpG}$ combined with vaccine had antibodies compared with $0 \%$ of the subjects receiving vaccine alone. Two and four weeks after the second dose, antibody titres were more than 30-fold higher in subjects receiving vaccine plus $\mathrm{CpG}$ versus vaccine alone (85). In a second double-blind study (86), CpG ODNs coadministered with the Fluarix
(GlaxoSmithKline, USA) influenza virus vaccine did not increase the antibody titre in naive recipients compared with vaccine alone, but did increase antibody levels in subjects with pre-existing influenza virus-specific antibodies. Furthermore, following in vitro restimulation, peripheral blood mononuclear cells from individuals immunized with vaccine plus $\mathrm{CpG}$ ODNs produced higher levels of IFN $-\gamma$ than did control vaccines (86). No serious adverse events attributed to the use of CpG ODNs were observed.

It has been demonstrated that $\mathrm{CpG} O \mathrm{ODN}$, a ligand for TLR9, serves as an effective adjuvant for mucosal vaccines (37). Gallichan et al (78) showed that intranasal administration of purified envelope glycoprotein $(\mathrm{gB})$ from HSV-2 plus $\mathrm{CpG} \mathrm{ODN}$ as an adjuvant induces strong gB-specific immunoglobulin (Ig) A and IgG in the vaginal tract (persisting throughout the estrous cycle), as well as systemic and genital gB-specific cytotoxic $\mathrm{T}$ lymphocytes, and protects against lethal IVAG HSV-2 infection. Subsequently, Dumais et al (87) showed that intranasal immunization with inactivated gp120-depleted HIV-1 plus CpG ODN induces antiHIV IgA in the genital tract and HIV-specific $\mathrm{T}$ cell-mediated immune responses, including the production of IFN- $\gamma$ and beta-chemokines. Furthermore, mice immunized intranasally with $\mathrm{HIV}-1$ plus $\mathrm{CpG}$ induced CD8+ $\mathrm{T}$ cells in the genital tract, providing cross-clade protection against IVAG challenge with recombinant vaccinia viruses expressing HIV-1 Gag from different clades (88). More recently, although the genital tract has been considered to be a poor immune inductive site, especially following immunization with nonreplicating antigens, Kwant and Rosenthal (89) showed that IVAG immunization of female mice with recombinant subunit HSV-2 gB plus CpG induced higher levels of $\mathrm{gB}$-specific $\operatorname{IgG}$ and $\operatorname{IgA}$ antibodies in serum and vaginal washes versus mice immunized with antigen alone, and that mice immunized with gB plus $\mathrm{CpG}$ were better protected against vaginal infection with HSV-2. Thus, it is possible to induce protective immune responses following IVAG immunization with a nonreplicating subunit protein antigen, provided an appropriate mucosal adjuvant is used.

Similarly, TLR4 agonists, such as monophosphoryl lipid A (a chemically modified LPS that retains many of the immunostimulatory properties of LPS without its toxic effects), is also an effective mucosal adjuvant (90). Mice immunized intranasally with influenza hemagglutinin plus MPL (clinical grade formulation of monophosphoryl lipid A) generated mucosal immune responses, including $\operatorname{IgA}$ in vaginal washes, and enhanced protection against intranasal challenge with influenza virus. Novel approaches to vaccine development could exploit the effects of TLR-activating compounds on innate and adaptive immune responses, especially at mucosal surfaces.

In a novel approach to understand what makes 'successful' vaccines, Bali Pulendran and his associates recently examined yellow fever virus 17D (YF-17D) vaccine. The YF-17D vaccine has been administered to over 400 million people worldwide and has been shown to induce neutralizing antibodies that last as long as 35 years after a single immunization. Their recent studies (91) showed that YF-17D activates multiple subsets of DCs by signalling through multiple TLRs, including TLR2, 7, 8 and 9 (91). The activation of multiple subsets of DCs resulted in diverse types of adaptive immune responses (92). Thus, triggering multiple TLRs may generate immune 
synergy. Based on these types of investigations, future vaccines may consist of multiple TLR ligands that provide both immune synergy and immune diversity.

\section{CONCLUSIONS}

The innate immune system is evolutionarily ancient and provides our first line of defense against infections. We have recently become aware that the innate immune system uses multiple PRR families to detect highly conserved PAMPs. Overall, the innate system is poised to protect all avenues of pathogen invasion, with TLRs detecting pathogens at the cellular plasma membrane and in endosomal/lysosomal cellular compartments, while NOD proteins and RNA helicases detect infection in the cytoplasm. The variety of PRR families permits not only diversity of ligand recognition but also functional diversity with regard to induced responses. Although we are in the early stages of understanding innate immune sensing and responses, there is a growing amount of evidence suggesting that the use of ligands, agonists and antagonists of innate immunity ('innate immunologicals') can serve as novel approaches to provide almost immediate protection against, or treatment of, bacterial, viral or parasitic infections. Furthermore, the renewed recognition of the importance of innate immunity in imitating and shaping adaptive immune responses, along with an increasing number of studies showing the effectiveness of TLR ligands and agonists as vaccine adjuvants, promises to lead to improved next-generation vaccines.

ACKNOWLEDGEMENTS: Dr Rosenthal is supported by a Career Scientist Award from the Ontario HIV Treatment Network (OHTN). The author is grateful for the continuing commitment and drive of some of his past and current Postdoctoral Fellows (Drs W Scott Gallichan, Nancy Dumais, Xiao-Dan Yao and Marie Estcourt), graduate students (including Dusan Sajic, Amanda Kwant, Janina Jiang, Sumiti Jain, Anna Drannik and Vera Tang), and technicians (Jennifer Newton and Amy Patrick). The author is also grateful for the collaboration of his colleagues, Drs Ali Ashkar and Charu Kaushic. This study was supported by grants from the Canadian Institutes of Health Research (CIHR), OHTN, the Canadian Network for Vaccines and Immunotherapeutics (CAN. VAC), and more recently, the Bill and Melinda Gates Foundation.

\section{REFERENCES}

1. Akira S, Uematsu S, Takeuchi O. Pathogen recognition and innate immunity. Cell 2006;124:783-801.

2. Hargreaves DC, Medzhitov R. Innate sensors of microbial infection. J Clin Immunol 2005;25:503-10.

3. Kawai T, Akira S. Innate immune recognition of viral infection. Nat Immunol 2006; 7:131-7.

4. Philpott DJ, Girardin SE. The role of Toll-like receptors and Nod proteins in bacterial infection. Mol Immunol 2004;41:1099-108.

5. Seth RB, Sun L, Chen ZJ. Antiviral innate immunity pathways. Cell Res 2006;16:141-7.

6. Janeway CA Jr, Medzhitov R. Introduction: The role of innate immunity in the adaptive immune response. Semin Immunol 1998; 10:349-50.

7. Janeway CA Jr. The immune system evolved to discriminate infectious nonself from noninfectious self. Immunol Today 1992;13:11-6.

8. Janeway CA Jr, Medzhitov R. Lipoproteins take their toll on the host. Curr Biol 1999;9:R879-82.

9. Stein D, Roth S, Vogelsang E, Nusslein-Volhard C. The polarity of the dorsoventral axis in the Drosophila embryo is defined by an extracellular signal. Cell 1991;65:725-35.
10. Lemaitre B, Nicolas E, Michaut L, Reichhart JM, Hoffmann JA The dorsoventral regulatory gene cassette spatzle/Toll/cactus controls the potent antifungal response in Drosophila adults. Cell 1996;86:973-83.

11. Kawai T, Akira S. Pathogen recognition with Toll-like receptors. Curr Opin Immunol 2005;17:338-44.

12. O'Neill LA. How Toll-like receptors signal: What we know and what we don't know. Curr Opin Immunol 2006;18:3-9.

13. Medzhitov R, Preston-Hurlburt P, Janeway CA Jr. A human homologue of the Drosophila Toll protein signals activation of adaptive immunity. Nature 1997;388:394-7.

14. Poltorak A, He X, Smirnova I, et al. Defective LPS signaling in $\mathrm{C} 3 \mathrm{H} / \mathrm{HeJ}$ and $\mathrm{C} 57 \mathrm{BL} / 10 \mathrm{ScCr}$ mice: Mutations in $\mathrm{Tl} 4$ gene. Science 1998;282:2085-8.

15. Takeda K, Kaisho T, Akira S. Toll-like receptors. Annu Rev Immunol 2003;21:335-76.

16. Takeuchi O, Hoshino K, Kawai T, et al. Differential roles of TLR2 and TLR4 in recognition of gram-negative and gram-positive bacterial cell wall components. Immunity 1999;11:443-51.

17. Gantner BN, Simmons RM, Canavera SJ, Akira S, Underhill DM. Collaborative induction of inflammatory responses by dectin-1 and Toll-like receptor 2. J Exp Med 2003;197:1107-17.

18. Hayashi F, Smith KD, Ozinsky A, et al. The innate immune response to bacterial flagellin is mediated by Toll-like receptor 5 . Nature 2001;410:1099-103.

19. Zhang D, Zhang G, Hayden MS, et al. A toll-like receptor that prevents infection by uropathogenic bacteria. Science 2004;303:1522-6.

20. Yarovinsky F, Zhang D, Andersen JF, et al. TLR11 activation of dendritic cells by a protozoan profilin-like protein. Science 2005;308:1626-9.

21. Latz E, Schoenemeyer A, Visintin A, et al. TLR9 signals after translocating from the ER to CpG DNA in the lysosome. Nat Immunol 2004;5:190-8.

22. Matsumoto M, Funami K, Tanabe M, et al. Subcellular localization of Toll-like receptor 3 in human dendritic cells. J Immunol 2003;171:3154-62.

23. Alexopoulou L, Holt AC, Medzhitov R, Flavell RA. Recognition of double-stranded RNA and activation of NF-kappaB by Toll-like receptor 3. Nature 2001;413:732-8.

24. Diebold SS, Kaisho T, Hemmi H, Akira S, Reis e Sousa C. Innate antiviral responses by means of TLR7-mediated recognition of single-stranded RNA. Science 2004;303:1529-31.

25. Heil F, Hemmi H, Hochrein H, et al. Species-specific recognition of single-stranded RNA via toll-like receptor 7 and 8 . Science 2004;303:1526-9.

26. Hemmi H, Kaisho T, Takeuchi O, et al. Small anti-viral compounds activate immune cells via the TLR7 MyD88-dependent signaling pathway. Nat Immunol 2002;3:196-200.

27. Jurk M, Heil F, Vollmer J, et al. Human TLR7 or TLR8 independently confer responsiveness to the antiviral compound R-848. Nat Immunol 2002;3:499.

28. Hemmi H, Takeuchi O, Kawai T, et al. A Toll-like receptor recognizes bacterial DNA. Nature 2000;408:740-5.

29. Coban C, Ishii KJ, Kawai T, et al. Toll-like receptor 9 mediates innate immune activation by the malaria pigment hemozoin. J Exp Med 2005;201:19-25.

30. Roach JC, Glusman G, Rowen L, et al. The evolution of vertebrate Toll-like receptors. Proc Natl Acad Sci USA 2005;102:9577-82

31. Barton GM, Kagan JC, Medzhitov R. Intracellular localization of Toll-like receptor 9 prevents recognition of self DNA but facilitates access to viral DNA. Nat Immunol 2006;7:49-56.

32. Akira S, Takeda K. Toll-like receptor signalling. Nat Rev Immunol 2004;4:499-511.

33. Iwasaki A, Medzhitov R. Toll-like receptor control of the adaptive immune responses. Nat Immunol 2004;5:987-95.

34. Bauer M, Redecke V, Ellwart JW, et al. Bacterial CpG-DNA triggers activation and maturation of human CD11c-, CD123+ dendritic cells. J Immunol 2001;166:5000-7.

35. Krug A, Towarowski A, Britsch S, et al. Toll-like receptor expression reveals $\mathrm{CpG}$ DNA as a unique microbial stimulus for plasmacytoid dendritic cells which synergizes with CD40 ligand to induce high amounts of IL-12. Eur J Immunol 2001;31:3026-37. 
36. Yao X-D, Fernandez S, Kelly MM, Kaushic C, Rosenthal KL. Tolllike receptors in murine vaginal epithelium is affected by the estrous cycle and stromal cells. J Reprod Immunol. (Submitted)

37. Ashkar AA, Rosenthal KL. Toll-like receptor 9, CpG DNA and innate immunity. Curr Mol Med 2002;2:545-56.

38. Inohara, Chamaillard, McDonald C, Nunez G. NOD-LRR proteins: Role in host-microbial interactions and inflammatory disease. Annu Rev Biochem 2005;74:355-83.

39. Strober W, Murray PJ, Kitani A, Watanabe T. Signalling pathways and molecular interactions of NOD1 and NOD2. Nat Rev Immunol 2006;6:9-20.

40. Yoneyama M, Kikuchi M, Natsukawa T, et al. The RNA helicase RIG-I has an essential function in double-stranded RNA-induced innate antiviral responses. Nat Immunol 2004;5:730-7.

41. Chamaillard M, Hashimoto M, Horie $\mathrm{Y}$, et al. An essential role for NOD1 in host recognition of bacterial peptidoglycan containing diaminopimelic acid. Nat Immunol 2003;4:702-7.

42. Girardin SE, Boneca IG, Carneiro LA, et al. Nod1 detects a unique muropeptide from gram-negative bacterial peptidoglycan. Science 2003;300:1584-7.

43. Girardin SE, Boneca IG, Viala J, et al. Nod2 is a general sensor of peptidoglycan through muramyl dipeptide (MDP) detection. J Biol Chem 2003;278:8869-72.

44. Inohara $\mathrm{N}$, Ogura $\mathrm{Y}$, Fontalba $\mathrm{A}$, et al. Host recognition of bacterial muramyl dipeptide mediated through NOD2. Implications for Crohn's disease. J Biol Chem 2003;278:5509-12.

45. Barnich N, Aguirre JE, Reinecker HC, Xavier R, Podolsky DK. Membrane recruitment of NOD2 in intestinal epithelial cells is essential for nuclear factor-\{kappa\}B activation in muramyl dipeptide recognition. J Cell Biol 2005;170:21-6.

46. Fritz JH, Girardin SE, Fitting C, et al. Synergistic stimulation of human monocytes and dendritic cells by Toll-like receptor 4 and NOD1 - and NOD2-activating agonists. Eur J Immunol 2005;35:2459-70.

47. Gutierrez O, Pipaon C, Inohara N, et al. Induction of Nod2 in myelomonocytic and intestinal epithelial cells via nuclear factorkappa B activation. J Biol Chem 2002;277:41701-5.

48. Hugot JP, Chamaillard M, Zouali H, et al. Association of NOD2 leucine-rich repeat variants with susceptibility to Crohn's disease. Nature 2001;411:599-603.

49. Ogura Y, Bonen DK, Inohara N, et al. A frameshift mutation in NOD2 associated with susceptibility to Crohn's disease. Nature 2001;411:603-6.

50. Viala J, Chaput C, Boneca IG, et al. Nod1 responds to peptidoglycan delivered by the Helicobacter pylori cag pathogenicity island. Nat Immunol 2004;5:1166-74.

51. Kato H, Sato S, Yoneyama M, et al. Cell type-specific involvement of RIG-I in antiviral response. Immunity 2005;23:19-28.

52. Breiman A, Grandvaux N, Lin R, et al. Inhibition of RIG-Idependent signaling to the interferon pathway during hepatitis $\mathrm{C}$ virus expression and restoration of signaling by IKKepsilon. J Virol 2005;79:3969-78.

53. Foy E, Li K, Sumpter R Jr, et al. Control of antiviral defenses through hepatitis $\mathrm{C}$ virus disruption of retinoic acid-inducible gene-I signaling. Proc Natl Acad Sci USA 2005;102:2986-91.

54. Stacey KJ, Blackwell JM. Immunostimulatory DNA as an adjuvant in vaccination against Leishmania major. Infect Immun 1999;67:3719-26.

55. Walker PS, Scharton-Kersten T, Krieg AM, et al. Immunostimulatory oligodeoxynucleotides promote protective immunity and provide systemic therapy for leishmaniasis via IL-12. and IFN-gamma-dependent mechanisms. Proc Natl Acad Sci USA 1999;96:6970-5.

56. Zimmermann S, Egeter O, Hausmann S, et al. CpG oligodeoxynucleotides trigger protective and curative Th1 responses in lethal murine leishmaniasis. J Immunol 1998;160:3627-30.

57. Krieg AM, Yi AK, Schorr J, Davis HL. The role of CpG dinucleotides in DNA vaccines. Trends Microbiol 1998;6:23-7.

58. Elkins KL, Rhinehart-Jones TR, Stibitz S, Conover JS, Klinman DM. Bacterial DNA containing CpG motifs stimulates lymphocyte-dependent protection of mice against lethal infection with intracellular bacteria. J Immunol 1999;162:2291-8.

59. Juffermans NP, Leemans JC, Florquin S, et al. CpG oligodeoxynucleotides enhance host defense during murine tuberculosis. Infect Immun 2002;70:147-52.

60. Ashkar AA, Bauer S, Mitchell WJ, Vieira J, Rosenthal KL. Local delivery of $\mathrm{CpG}$ oligodeoxynucleotides induces rapid changes in the genital mucosa and inhibits replication, but not entry, of herpes simplex virus type 2. J Virol 2003;77:8948-56.

61. Pyles RB, Higgins D, Chalk C, et al. Use of immunostimulatory sequence-containing oligonucleotides as topical therapy for genital herpes simplex virus type 2 infection. J Virol 2002;76:11387-96.

62. Sajic D, Ashkar AA, Patrick AJ, et al. Parameters of CpG oligodeoxynucleotide-induced protection against intravaginal HSV-2 challenge. J Med Virol 2003;71:561-8.

63. Klinman DM, Verthelyi D, Takeshita F, Ishii KJ. Immune recognition of foreign DNA: A cure for bioterrorism? Immunity 1999;11:123-9

64. Gramzinski RA, Doolan DL, Sedegah M, Davis HL, Krieg AM, Hoffman SL. Interleukin-12- and gamma interferon-dependent protection against malaria conferred by $\mathrm{CpG}$ oligodeoxynucleotide in mice. Infect Immun 2001;69:1643-9.

65. Weighardt H, Feterowski C, Veit M, Rump M, Wagner H, Holzmann B. Increased resistance against acute polymicrobial sepsis in mice challenged with immunostimulatory $\mathrm{CpG}$

oligodeoxynucleotides is related to an enhanced innate effector cell response. J Immunol 2000;165:4537-43.

66. Cristofaro P, Opal SM. Role of Toll-like receptors in infection and immunity: Clinical implications. Drugs 2006;66:15-29.

67. LeBouder E, Rey-Nores JE, Rushmere NK, et al. Soluble forms of Toll-like receptor (TLR) 2 capable of modulating TLR2 signaling are present in human plasma and breast milk. J Immunol 2003;171:6680-9.

68. Lynn M, Rossignol DP, Wheeler JL, et al. Blocking of responses to endotoxin by E5564 in healthy volunteers with experimental endotoxemia. J Infect Dis 2003;187:631-9.

69. Savov JD, Brass DM, Lawson BL, McElvania-Tekippe E, Walker JK Schwartz DA. Toll-like receptor 4 antagonist (E5564) prevents the chronic airway response to inhaled lipopolysaccharide. Am J Physiol Lung Cell Mol Physiol 2005;289:L329-37.

70. Hengge UR, Benninghoff B, Ruzicka T, Goos M. Topical immunomodulators - progress towards treating inflammation, infection, and cancer. Lancet Infect Dis 2001;1:189-98.

71. Klinman DM. Immunotherapeutic uses of $\mathrm{CpG}$ oligodeoxynucleotides. Nat Rev Immunol 2004:4:249-58.

72. Ito S, Ishii KJ, Shirota H, Klinman DM. CpG oligodeoxynucleotides improve the survival of pregnant and fetal mice following Listeria monocytogenes infection. Infect Immun 2004; $72: 3543-8$.

73. Shattock RJ, Moore JP. Inhibiting sexual transmission of HIV-1 infection. Nat Rev Microbiol 2003;1:25-34.

74. Ashkar AA, Yao XD, Gill N, Sajic D, Patrick AJ, Rosenthal KL. Toll-like receptor (TLR)-3, but not TLR4, agonist protects against genital herpes infection in the absence of inflammation seen with CpG DNA. J Infect Dis 2004;190:1841-9.

75. Singh M, O'Hagan D. Advances in vaccine adjuvants. Nat Biotechnol 1999;17:1075-81.

76. Chu RS, Targoni OS, Krieg AM, Lehmann PV, Harding CV. CpG oligodeoxynucleotides act as adjuvants that switch on T helper 1 (Th1) immunity. J Exp Med 1997;186:1623-31.

77. Davis HL, Weeratna R, Waldschmidt TJ, Tygrett L, Schorr J, Krieg AM. CpG DNA is a potent enhancer of specific immunity in mice immunized with recombinant hepatitis B surface antigen. J Immunol 1998;160:870-6.

78. Gallichan WS, Woolstencroft RN, Guarasci T, McCluskie MJ, Davis HL, Rosenthal KL. Intranasal immunization with $\mathrm{CpG}$ oligodeoxynucleotides as an adjuvant dramatically increases IgA and protection against herpes simplex virus- 2 in the genital tract. J Immunol 2001;166:3451-7.

79. Lipford GB, Bauer M, Blank C, Reiter R, Wagner H, Heeg K. $\mathrm{CpG}$-containing synthetic oligonucleotides promote $\mathrm{B}$ and cytotoxic $\mathrm{T}$ cell responses to protein antigen: A new class of vaccine adjuvants. Eur J Immunol 1997;27:2340-4.

80. McCluskie MJ, Davis HL. CpG DNA is a potent enhancer of systemic and mucosal immune responses against hepatitis B surface antigen with intranasal administration to mice. J Immunol 1998;161:4463-6.

81. Sun S, Kishimoto H, Sprent J. DNA as an adjuvant: Capacity of insect DNA and synthetic oligodeoxynucleotides to augment T cell responses to specific antigen. J Exp Med 1998;187:1145-50.

82. Weiner GJ, Liu HM, Wooldridge JE, Dahle CE, Krieg AM. Immunostimulatory oligodeoxynucleotides containing the $\mathrm{CpG}$ 
motif are effective as immune adjuvants in tumor antigen immunization. Proc Natl Acad Sci USA 1997;94:10833-7.

83. Moldoveanu Z, Love-Homan L, Huang WQ, Krieg AM. CpG DNA, a novel immune enhancer for systemic and mucosal immunization with influenza virus. Vaccine 1998;16:1216-24.

84. Davis HL, Suparto II, Weeratna RR, et al. CpG DNA overcomes hyporesponsiveness to hepatitis B vaccine in orangutans. Vaccine 2000;18:1920-4.

85. Halperin SA, Van Nest G, Smith B, Abtahi S, Whiley H, Eiden JJ. A phase I study of the safety and immunogenicity of recombinant hepatitis B surface antigen co-administered with an immunostimulatory phosphorothioate oligonucleotide adjuvant. Vaccine 2003;21:2461-7.

86. Cooper CL, Davis HL, Morris ML, et al. Safety and immunogenicity of CPG 7909 injection as an adjuvant to Fluarix influenza vaccine. Vaccine 2004;22:3136-43.

87. Dumais N, Patrick A, Moss RB, Davis HL, Rosenthal KL. Mucosal immunization with inactivated human immunodeficiency virus plus $\mathrm{CpG}$ oligodeoxynucleotides induces genital immune responses and protection against intravaginal challenge. J Infect Dis 2002;186:1098-105.

88. Jiang JQ, Patrick A, Moss RB, Rosenthal KL. CD8+ T-cellmediated cross-clade protection in the genital tract following intranasal immunization with inactivated human immunodeficiency virus antigen plus $\mathrm{CpG}$ oligodeoxynucleotides. J Virol 2005;79:393-400.

89. Kwant A, Rosenthal KL. Intravaginal immunization with viral subunit protein plus $\mathrm{CpG}$ oligodeoxynucleotides induces protective immunity against HSV-2. Vaccine 2004;22:3098-104.

90. Persing DH, Coler RN, Lacy MJ, et al. Taking toll: Lipid A mimetics as adjuvants and immunomodulators. Trends Microbiol 2002;10:S32-37.

91. Querec T, Bennouna S, Alkan S, et al. Yellow fever vaccine YF-17D activates multiple dendritic cell subsets via TLR2, 7, 8, and 9 to stimulate polyvalent immunity. J Exp Med 2006;203:413-24.

92. Pulendran B, Ahmed R. Translating innate immunity into immunological memory: Implications for vaccine development. Cell 2006;124:849-63. 


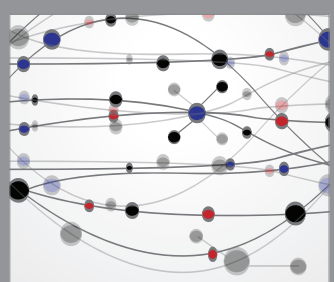

The Scientific World Journal
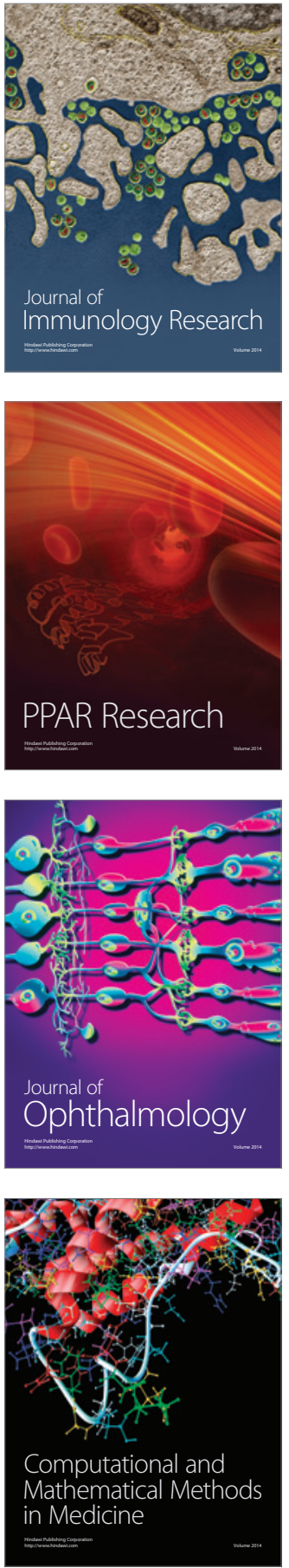

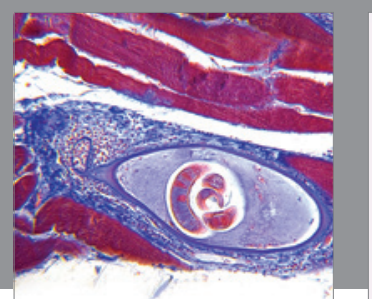

Gastroenterology Research and Practice

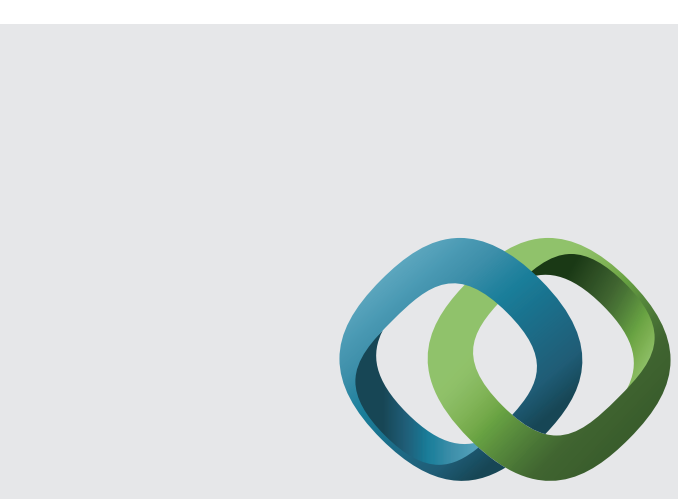

\section{Hindawi}

Submit your manuscripts at

http://www.hindawi.com
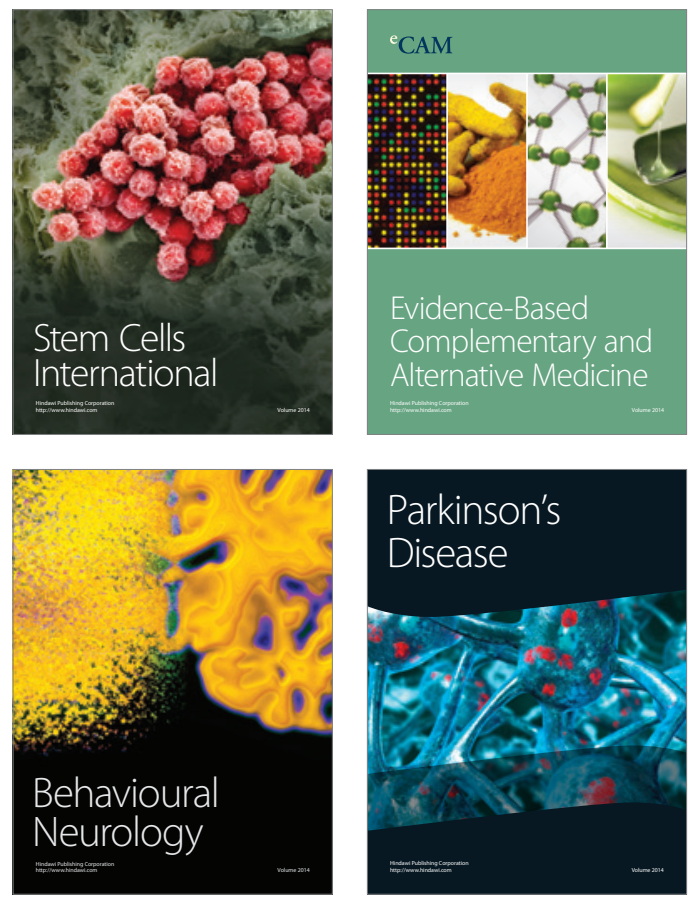
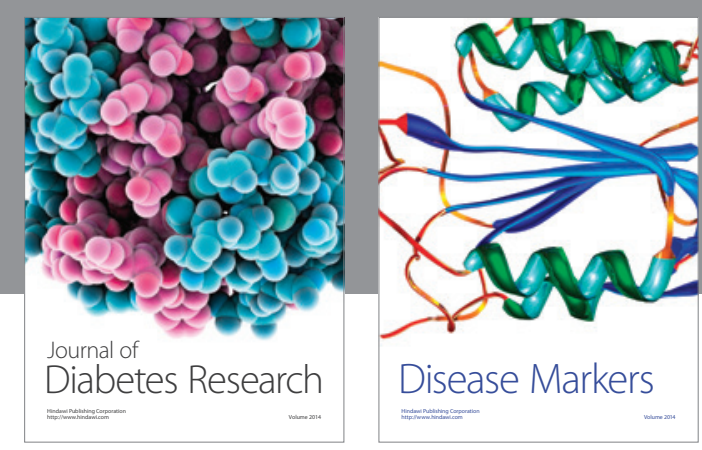

Disease Markers
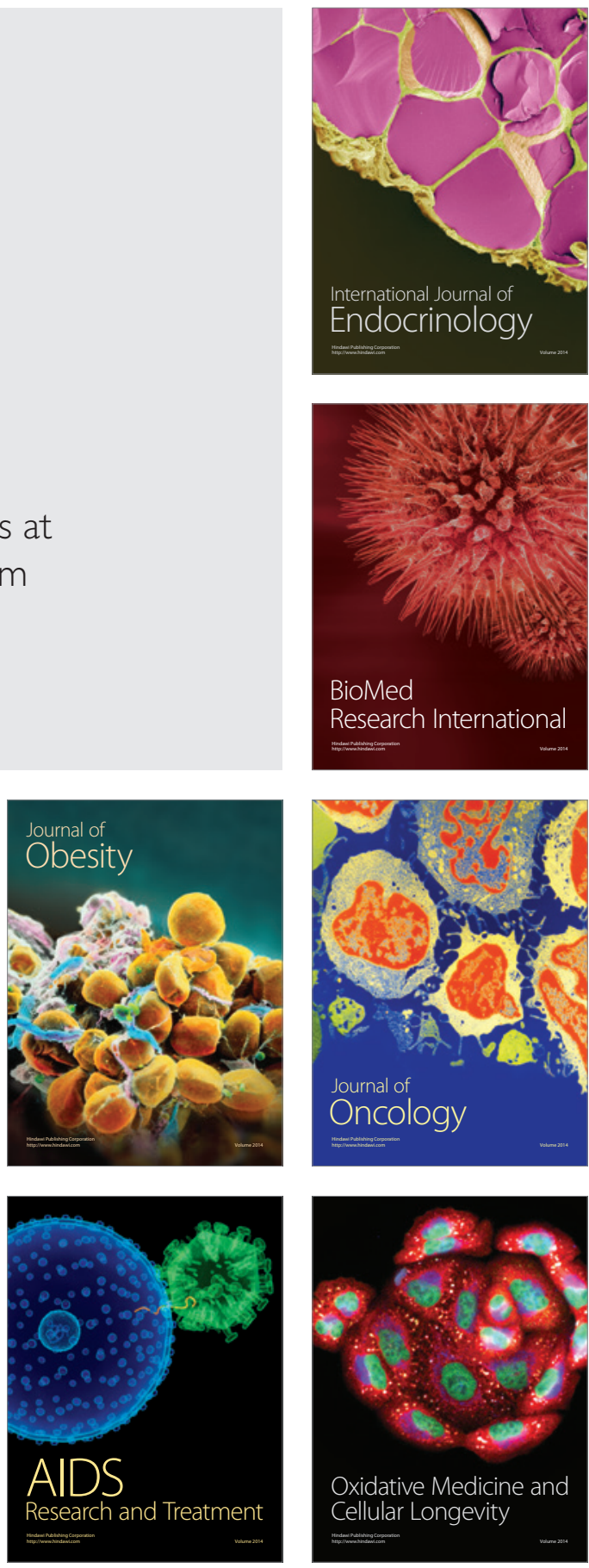